\title{
QUALITY OF STROKE CARE IN SLOVAKIA.
}

Gdovinová Z1 ${ }^{1}$, Brozman $M^{2}$, Hanáčková $E^{3}$ Serdahely $V^{4}$, Balušík $I^{5}$, Krastev $G^{6}$, Petrík $\mathrm{O}^{7}$, Droppa ${ }^{8}$, Gurčík $\mathrm{L}^{9}$, Turčáni $\mathrm{P}^{10}$, Krivošík $\mathrm{M}^{11}$, Leško $\mathrm{N}^{1}$, Baráková $\mathrm{A}^{12}$ and Vosko $\mathrm{MR}^{13}$

${ }^{1}$ Department of Neurology, Faculty of Medicine, P.J. Safarik University and University Hospital L. Pasteur, Košice, Slovakia, ${ }^{2}$ Department of Neurology, Faculty Hospital Nitra, Slovakia, ${ }^{3}$ Department of Neurology, General Hospital FORLIFE, Slovakia, ${ }^{4}$ Department of Neurology, Faculty Hospital Skalica, Slovakia, ${ }^{5}$ Department of Neurology, Hospital Rožňava, ${ }^{6}$ Department of Neurology, Faculty Hospital Trnava, Slovakia, ${ }^{7}$ Department of Neurology, Hospital Galanta ProCare, Slovakia, ${ }^{8}$ Department of Neurology, Hospital Brezno, Slovakia, ${ }^{9}$ Department of Neurology, General Hospital Levoča, Slovakia, 10 . Department of Neurology, Faculty of Medicine, Comenius University and University Hospital Bratislava, Slovakia, ${ }^{11} 1$ l. Department of Neurology, Faculty of Medicine, Comenius University and University Hospital Kramáre, Bratislava, Slovakia, ${ }^{12}$ National Health Information Center, Bratislava, Slovakia, ${ }^{13}$ ESO-EAST Steering Committee, Department of Neurology 2, Kepler University Clinic, Linz, Austria

\section{Background:}

Intravenous thrombolysis (IVT) and endovascular treatment (EVT) significantly improve the outcome for ischaemic stroke (IS), but the results also depends on time. Quality control is therefore very important.
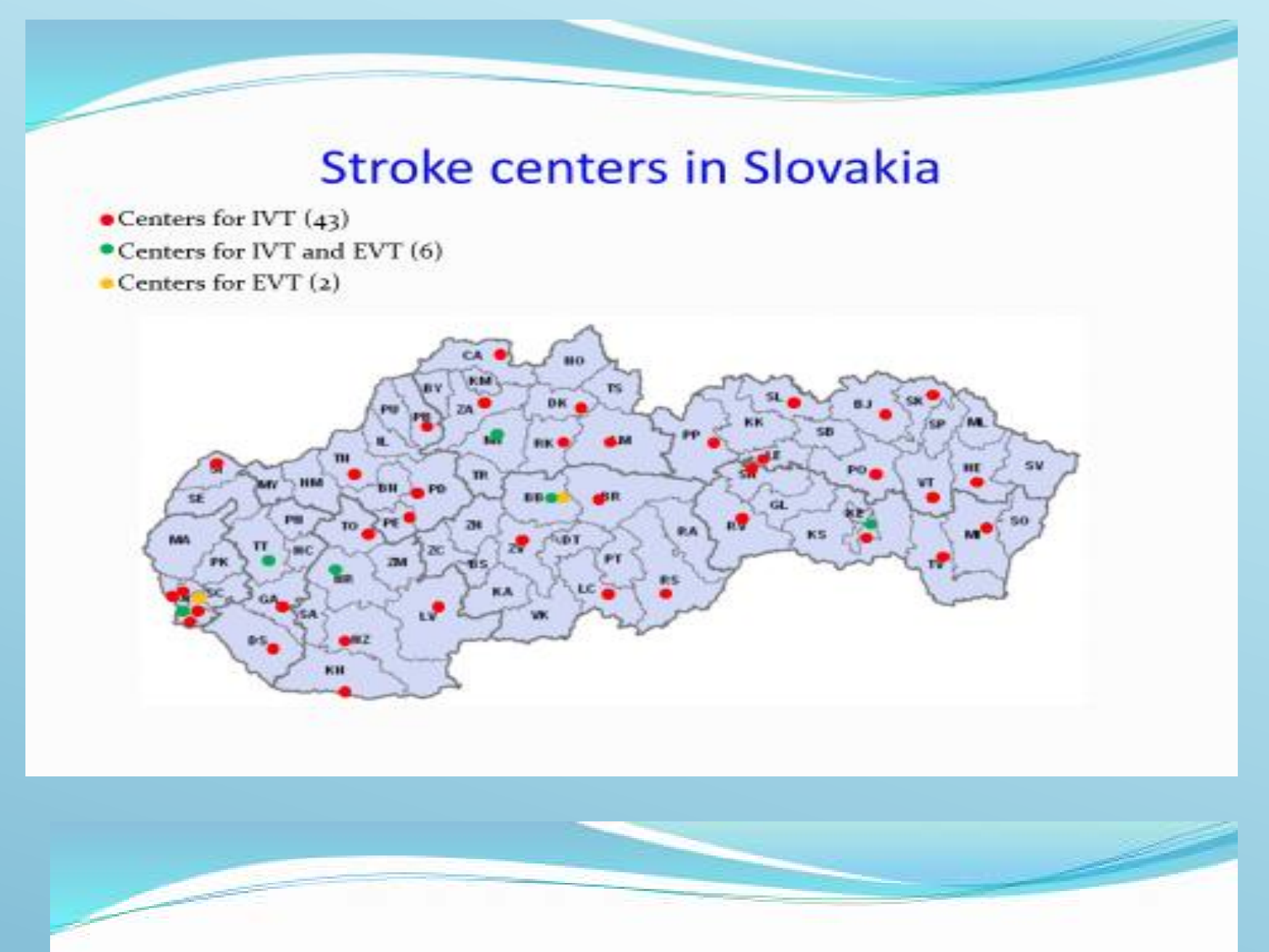

\section{Patients hospitalized in March 2017}

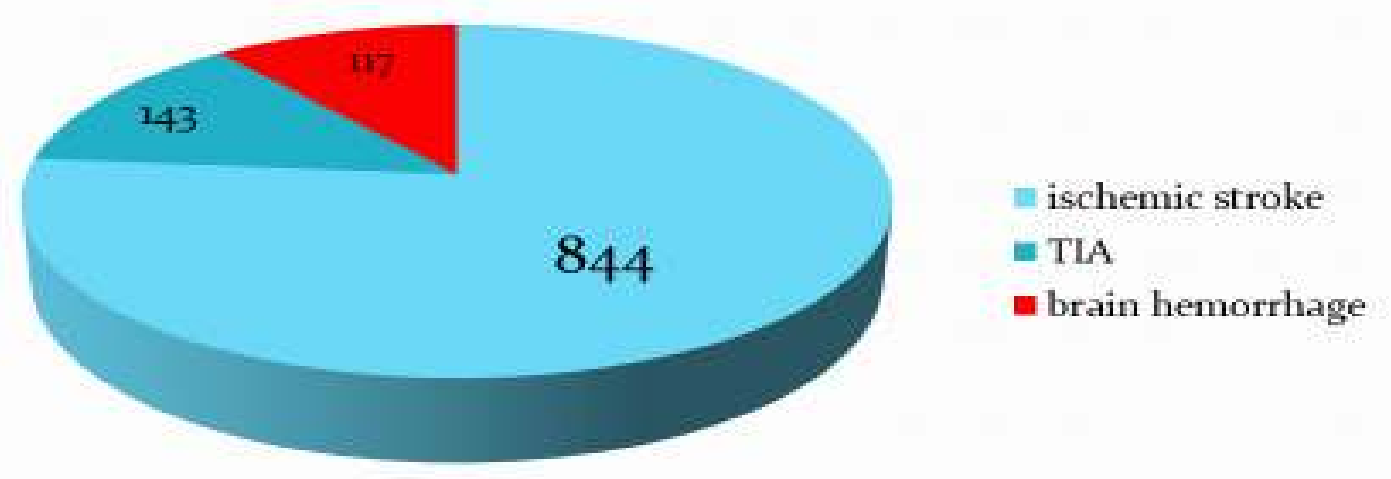

Acute treatment (IVT, EVT, IVT + EVT) in Slovakia in March 2017

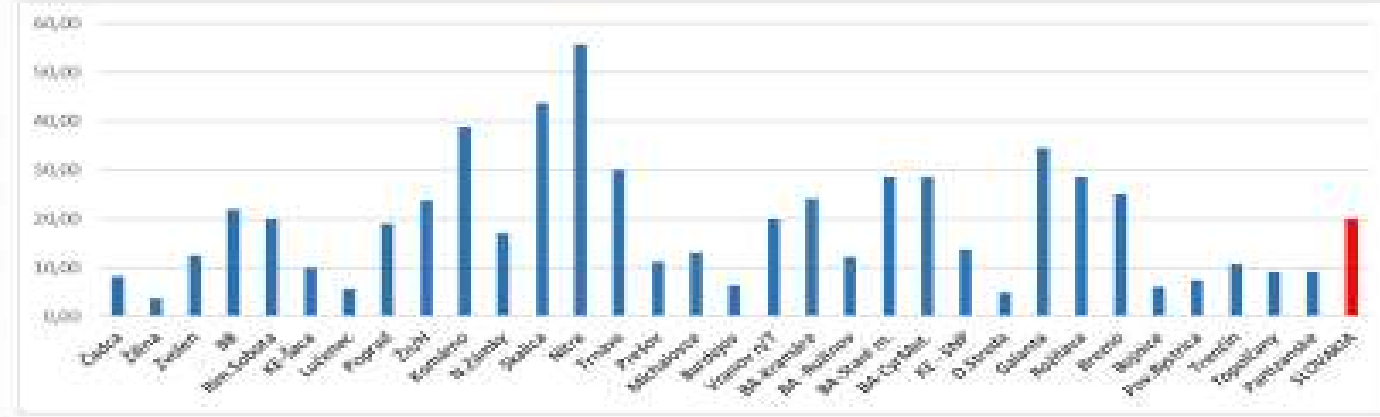

IVT $-14,8 \%, E V T-3.3 \%$
Methods:

We analysed the data from National stroke registry (mandatory for all stroke centers in Slovakia) in March 2017 to evaluate the quality parameters.

In the same time data from Registry of Stroke Care Quality (RES-Q) in ESO EAST countries were analysed.

Door-to needle time, Slovakia March 2017

- Different hospitals
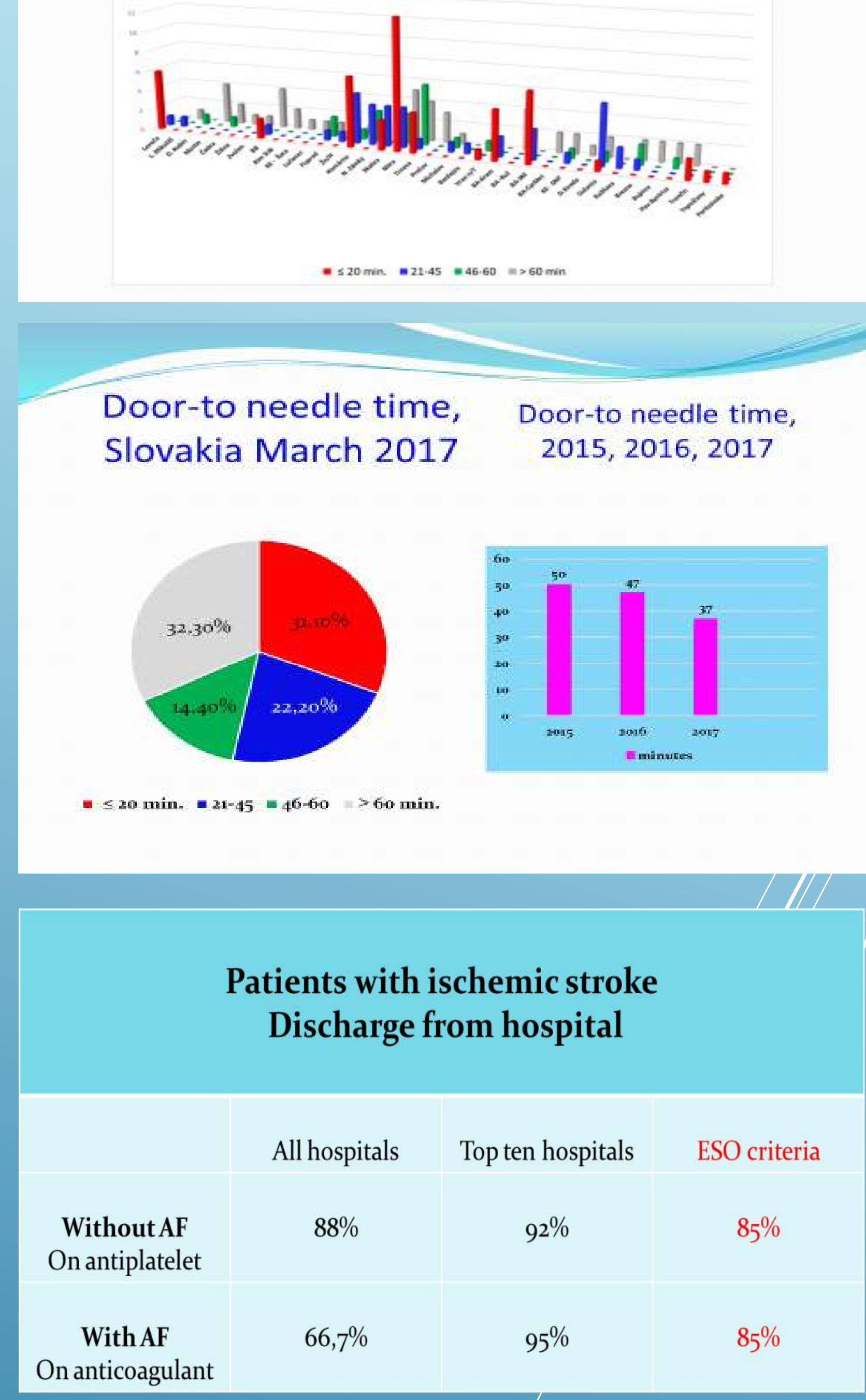

\section{Conclusion}

- ESO quality criteria are met in the most of the hospitals

- Our goal is to meet them in all hospitals

$\Rightarrow$ new guidelines with Ministry of Health - end of 2017

$\Rightarrow$ set up a network of primary and secondary stroke centers

$\Rightarrow$ improved collaboration with rescue services 